\title{
Elution of Metals with Artificial Sweat/Saliva from Inorganic Antimicrobials/Processed Cloths and Evaluation of Antimicrobial Activity of Cloths
}

\author{
Harunobu Nakashima, ${ }^{*, a}$ Naoko Miyano, ${ }^{a}$ and Tadashi Takatuka ${ }^{b}$ \\ ${ }^{a}$ Department of Environmental Health, Osaka Prefectural Institute of Public Health, 1-3-69 Nakamichi, Higashinari-ku, Osaka 537- \\ 0025, Japan and ${ }^{b}$ Technology Research Institute of Osaka Prefecture, 2-7-1 Ayumino, Izumi, Osaka 594-1157, Japan
}

(Received December 21, 2007; Accepted May 20, 2008; Published online June 4, 2008)

\begin{abstract}
Inorganic agents, such as $\mathrm{Ag}, \mathrm{Cu}$, and $\mathrm{Zn}$ compounds, are known to be relatively safe, and these agents are used in many products. In Europe, the standard levels of heavy metals eluted with artificial sweat and saliva are specified in the self-imposed safety criteria (OEKOTEX Standard) for textile products. We prepared metal zeolites $(\mathrm{Ag}, \mathrm{Cu}, \mathrm{Zn}$, and $\mathrm{Cr}$ ) and standard cloths loaded with these zeolites and a silver antimicrobial agent, AG300. The agents, standard processed cloths, and regions of commercially available products in which metals were detected at a high concentration were subjected to metal elution with artificial sweat (JIS L 0848: 2004), saliva (BS 6684: 1987), and purified water according to the JIS shake-flask antimicrobial test method (JIS L 1902-1900). The metal concentrations in the extracts were measured using an inductively coupled plasma-mass spectrometry (ICP-MS). A similar tendency was noted in elution from the agents, standard processed cloths, and commercial products. No metals were eluted with purified water alone, while the metals were eluted with artificial sweat and saliva. Large amounts of $\mathrm{Cu}$ and $\mathrm{Zn}$ were eluted, the elution of $\mathrm{Ag}$ was low, and almost no $\mathrm{Cr}$ was eluted. Furthermore, the antimicrobial activity of the standard processed cloths was evaluated in the antimicrobial test (JIS L 1902: 2002) using Staphylococcus aureus (S. aureus) and Klebsiella pneumoniae (K. pneumoniae). Cu- and Ag (Ag zeolite and AG300)-processed cloths exhibited strong antimicrobial activities against both bacteria. Zn-processed cloth also showed antimicrobial activity against $S$. aureus.
\end{abstract}

Key words _ _ inorganic antimicrobial agents, artificial sweat, artificial saliva, inductively coupled plasma atomic emission spectrometry, inductively coupled plasma-mass spectrometry, evaluation of antimicrobial activity

\section{INTRODUCTION}

Antimicrobial agents used in antimicrobialprocessed products are classified into inorganic, organic, and natural organic compounds. ${ }^{1-3)}$ Inorganic agents, such as $\mathrm{Ag}, \mathrm{Cu}$, and $\mathrm{Zn}$ compounds, are known to be relatively safe, and these agents are used in many types of household and medical products due to their good balance between antimicrobial activity and endurance. ${ }^{3-6)}$ However, patients with metal allergy due to $\mathrm{Cu}$ or $\mathrm{Zn}$ have been reported. ${ }^{7-12)}$ For fiber products that come into contact with the skin, excessive use of processing antimicrobials has been suggested to upset the balance of indigenous bacteria in the skin, induc-

\footnotetext{
*To whom correspondence should be addressed: Department of Environmental Health, Osaka Prefectural Institute of Public Health, 1-3-69 Nakamichi, Higashinari-ku, Osaka 537-0025, Japan. Tel.: +81-6-6972-1321; Fax: +81-6-6972-2393; E-mail: hrnakaji@iph.pref.osaka.jp
}

ing disorders such as dermatitis. In Europe, the OEKOTEX Standard ${ }^{13,14)}$ comprises self-imposed safety criteria for textile products. This standard sets the value limits for the elution of heavy metals (such as $\mathrm{Hg}, \mathrm{Cr}, \mathrm{Cu}$, and $\mathrm{Ni}$ ) with artificial sweat and saliva, with particularly strict limits for products for infants. Although there is a movement toward the use of this standard in Japan, no such self-imposed restriction standard has yet been established. In the OEKOTEX Standard, the elution method, amount of solution, elution time, and metal measurement methods are closed. For the establishment of such guidelines in Japan, we have evaluated the safety of inorganic antimicrobials. ${ }^{15-17)}$ First, analysis of metals in commercially available products was performed by X-ray fluorescence spectrometry and inductively coupled plasma atomic emission spectrometry (ICP-AES). ${ }^{16,17)}$ This study was performed to establish limits on the amount of metal elution from processed products. ${ }^{15,16)}$ As 
inorganic antimicrobials, metal zeolites containing $\mathrm{Ag}, \mathrm{Cu}$, or $\mathrm{Zn}$ are widely used. ${ }^{18-20)}$ Therefore, we prepared metal zeolites and standard cloths processed with these zeolites or Novaron AG300 as an $\mathrm{Ag}$ antimicrobial agent, and measured metal elution with artificial sweat/saliva using inductively coupled plasma-mass spectrometry (ICP-MS). Similar elution tests were also performed on commercially available antimicrobial products that showed a high metal concentration. ${ }^{16,17)}$ In addition, the antimicrobial activity of standard processed cloths was evaluated with the antimicrobial test method (JIS L 1902: 2002) ${ }^{21)}$ to confirm their antimicrobial effects.

\section{MATERIAL AND METHODS}

Preparation of Metal Zeolites — Inorganic antimicrobials include $\mathrm{Ag}, \mathrm{Cu}$, and $\mathrm{Zn}$ compounds. Therefore zeolites of these metals and a $\mathrm{Cr}$ zeolite with antimicrobial activity were prepared. Zeolite was used as a synthetic zeolite A-4 powder (75 $\mu \mathrm{m}$ : Wako Pure Chemical Industries, Ltd., Osaka, Japan). Silver nitrate (anhydrous), copper sulfate (pentahydrate), zinc sulfate (heptahydrate), and chromium nitrate (nonahydrate) were analytical-grade reagents (Wako Pure Chemical Industries, Ltd.). As purified water Milli-Q water after passing through Milli RO 5 plus and Milli Q plus (Millipore Corporation) was used.

Each metal solution was prepared so that the metal content was $5 \mathrm{wt} \%$ of the metal zeolite. Each metal salt $(0.15748 \mathrm{~g}$ silver nitrate, $0.39293 \mathrm{~g}$ copper sulfate, $0.43976 \mathrm{~g}$ zinc sulfate, and $0.76958 \mathrm{~g}$ chromium nitrate) was weighed in a 500-ml polypropylene beaker and dissolved in $200 \mathrm{ml}$ of purified water. Zeolite $(2.0 \mathrm{~g})$ was added to this solution and suspended by ultrasonication at room temperature $\left(20-24^{\circ} \mathrm{C}\right)$ for $24 \mathrm{hr}$. The suspension was passed through a polycarbonate membrane filter (pore size, $0.2 \mu \mathrm{m}$ : Advantech, California, U.S.A.), and the metal zeolite was collected. This metal zeolite was vacuum-dried at $60^{\circ} \mathrm{C}$ for $72 \mathrm{hr}$.

Preparation of Standard Processed Cloths Standard processed cloths were prepared by fixing each metal zeolite or Novaron AG300 (antimicrobial agent in which silver is carried by zirconium phosphate; Toagosei Co., Ltd., Tokyo, Japan) using the binder Light-Epoch S-60NFE (Kyoeisha Chemical Co., Ltd., Osaka, Japan). This binder contains
$25 \%$ effective components (drug components effective for antimicrobial fixation to cloth). Each metal antimicrobial and the resin binder were suspended in purified water so that the weight of the agent and that of the effective components of the binder were equal. Each suspension was diluted in purified water so that the percentage of the final metal antimicrobial weight was $1 \%$ or $2 \%$ of the weight of the fiber (o.w.f.). White cotton fabric [Japanese Standards Association (Tokyo, Japan), JIS L 0803, Kanakin No.3] was immersed in each solution and wrung using a mangle (Tsujii Machine Manufacturing Co., Ltd., Osaka, Japan) with a cloth: suspension weight ratio of $1: 1$. The cloth was dried at $110^{\circ} \mathrm{C}$ using a hot air-circulating baking machine (Daiei Kagaku Seiki Mfg. Co., Ltd., Kyoto, Japan) for $1 \mathrm{hr}$ for the fixation of the metal antimicrobial to the cloth.

Quantification of Metals in Antimicrobials and Processed Cloths Using ICP-AES — The metal antimicrobials (metal zeolites and AG300) and standard processed cloths were analyzed. The analyzed elements were $\mathrm{Ag}, \mathrm{Cu}, \mathrm{Zn}$, and $\mathrm{Cr}$ with bactericidal activity and $\mathrm{Al}$ as a component of antimicrobial zeolites. ${ }^{18)}$ As the standard solution, the custom-made multielement standard XSTC-13 (SPEX Centriprep Inc., New Jersey, U.S.A.) containing the metals for measurement was used. Nitric acid for poisonous metal analysis (Kanto Chemical Co., Inc., Tokyo, Japan) and Milli-Q water as purified water were also used.

ICP-AES was performed using an IRIS 1000 (Thermo Electron Corp., Kanagawa, Japan) under the following conditions: radio frequency power, $1150 \mathrm{~W}$; auxiliary gas flow, $0.5 \mathrm{l} / \mathrm{min}$; nebulizer pressure, $26.06 \mathrm{psi}$; and pump rate, $130 \mathrm{rpm}$. The main analysis wavelengths were: $\mathrm{Cu}, 324.757 \mathrm{~nm}$; Ag, 328.068 nm; Zn, 213.856 nm; Cr, 267.716 nm; and $\mathrm{Al}, 309.271 \mathrm{~nm}$. Depending on samples, wavelengths with less interference were used. The calibration curve of each metal showed a good linearity in the range of $0-1.0 \mu \mathrm{g} / \mathrm{ml}$ (correlation coefficient, 0.991-1.000).

Test solutions were prepared via the following procedure: $10 \mathrm{mg}$ of metal antimicrobial and $100 \mathrm{mg}$ of standard processed cloth were ashed. Each sample was put into a 50-ml Teflon vessel, mixed with $5 \mathrm{ml}$ of concentrated nitric acid, and ashed in a microwave digestion system (ETHOS model 900: Milestone General Co., Ltd., Kanagawa, Japan) continuously at a power of $300 \mathrm{~W}$ for $4 \mathrm{~min}, 400 \mathrm{~W}$ for $6 \mathrm{~min}$, and $800 \mathrm{~W}$ for 
15 min. After acid degradation, the samples were placed in a beaker. Following the addition of $5 \mathrm{ml}$ of nitric acid $0.1 \mathrm{M}$, the samples were heated on a hotplate for $10 \mathrm{~min}$, placed in test tubes, and mixed with nitric acid $0.1 \mathrm{M}$ to obtain a volume of $20 \mathrm{ml}$ as the test solution. Recovery experiments showed a good recovery rate (94-101\%) for each metal.

Metal Elution Experiments — Metal antimicrobials (metal zeolites and AG300), standard cloths processed with these agents, and 20 commercially available antimicrobial products (20 regions) in which metals were detected at a high concentration ${ }^{16,17)}$ were used for elution experiments.

Acidic artificial sweat ( $\mathrm{pH} 5.5)$ and alkaline artificial saliva ( $\mathrm{pH} 8.0$ ) were prepared by the method described in the "Test method for color fastness to perspiration" (JIS L 0848: 2004). ${ }^{22)}$ For the preparation of acidic artificial sweat, L-histidine hydrochloride monohydrate $(0.5 \mathrm{~g}), \mathrm{NaCl}(5 \mathrm{~g})$, and $\mathrm{Na}_{2} \mathrm{HPO}_{4} \cdot 12 \mathrm{H}_{2} \mathrm{O}(2.2 \mathrm{~g})$ were dissolved in purified water, mixed with $\mathrm{NaOH} 0.1 \mathrm{M}(15 \mathrm{ml})$ to adjust the $\mathrm{pH}$ to 5.5 , and $1000 \mathrm{ml}$ of the solution was obtained. For the preparation of alkaline artificial sweat, Lhistidine hydrochloride monohydrate $(0.5 \mathrm{~g}), \mathrm{NaCl}$ $(5 \mathrm{~g})$, and $\mathrm{Na}_{2} \mathrm{HPO}_{4} \cdot 12 \mathrm{H}_{2} \mathrm{O}(5 \mathrm{~g})$ were dissolved in pure water, mixed with $\mathrm{NaOH} 0.1 \mathrm{M}(25 \mathrm{ml})$ to adjust the $\mathrm{pH}$ to 8.0 , and $1000 \mathrm{ml}$ of the solution was obtained. Artificial saliva was prepared by the method described in BS 6684 British Standard Specification for Safety Harnesses, 1987. ${ }^{23)}$ In this study, a solution ( $\mathrm{pH} 2.3$ ) obtained by dissolving $\mathrm{NaCl}(4.5 \mathrm{~g}), \mathrm{KCl}(0.3 \mathrm{~g}), \mathrm{Na}_{2} \mathrm{SO}_{4}(0.4 \mathrm{~g}), \mathrm{NH}_{4} \mathrm{Cl}$ $(0.4 \mathrm{~g})$, DL-lactic acid $(3.0 \mathrm{~g})$, and urea $(0.2 \mathrm{~g})$ in purified water $(1000 \mathrm{ml})$ was used.

Elution experiments of the metal antimicrobials (metal zeolites, AG300) were performed using the following procedure: Each antimicrobial $(0.1 \mathrm{~g})$ plus artificial sweat, saliva, or purified water $(10 \mathrm{ml})$ were placed in a beaker and stirred for $1 \mathrm{~min}$ to create an antimicrobial suspension. The suspension was passed through a membrane filter (pore size $0.2 \mu \mathrm{m}, \phi 47 \mathrm{~mm}$, Japan Millipore JGWP04700).

Metal elution from the standard cloths and commercially available antimicrobial products was performed using the JIS shake-flask antimicrobial test method (JIS L 1902: 1990). ${ }^{24)}$ Each cloth (0.75 g) was put into a 200-ml Erlenmeyer flask and shaken at $310 \mathrm{rpm}$ using a wrist-action shaker at room temperature $\left(20^{\circ} \mathrm{C}\right)$ for $1 \mathrm{hr}$. The obtained eluate was passed through a membrane filter (pore size $0.2 \mu \mathrm{m})$.
Determination of Metals Using ICP-MS - After elution with artificial sweat/saliva/purified water from the antimicrobials, standard processed cloths, and commercially available antimicrobial products, $\mathrm{Ag}, \mathrm{Cu}, \mathrm{Zn}$, and $\mathrm{Cr}$ in the eluate were determined using ICP-MS. As a metal standard solution, the multielement standard XSTC-13 (SPEX Centriprep Inc.) was used. Nitric acid was employed as an ultrapure reagent (Kanto Chemical Co.). As purified water, Milli-Q water was used. With nitric acid $0.1 \mathrm{M}$, the standard solution and each eluate was diluted to $1 / 50$ or $1 / 100$ as a test solution.

ICP-MS analysis was performed with an ICPM8500 (Shimadzu Co., Ltd., Kyoto, Japan) under the following conditions: forward power, $1.2 \mathrm{KW}$; sampling depth, $5.0 \mathrm{~mm}$; Ar auxiliary gas flow rate, $7.01 \mathrm{l} / \mathrm{min}$, Ar plasma gas flow rate, $1.5 \mathrm{l} / \mathrm{min}$; and Ar carrier gas flow rate, $0.561 / \mathrm{min}$. The monitored ion was $m / z 65$ for $\mathrm{Cu}, m / z 66$ for $\mathrm{Zn}, m / z 52$ for $\mathrm{Cr}$, and $m / z 45$ for $\mathrm{Sc}$ as an internal standard. Ag was detected at $m / z 107$, and $\mathrm{Y}$ as an internal standard was detected at $m / z 89$. At $m / z 63$, where the highest sensitivity for $\mathrm{Cu}$ is obtained, a large amount of $\mathrm{Na}$ in artificial sweat/saliva interferes with measurement. Therefore $\mathrm{Cu}$ was detected at $\mathrm{m} / z 65$ with less interference. Each metal showed a calibration curve with a good linearity (correlation coefficient, $0.991-1.000)$ in the range of $0-1.0 \mathrm{ng} / \mathrm{ml}$.

Evaluation of the Antimicrobial Activity of Standard Processed Cloths Using the JIS Standard Test (JIS L 1902: 2002) ${ }^{21)}$ — Staphylococcus aureus (S. aureus) IFO 12732 as a gram-positive coccus and Klebsiella pneumoniae (K. pneumoniae) ATCC 4352 (IFO 13277) as a gram-negative bacillus were used as test microorganisms. The test bacteria were cultured with shaking in nutrient broth (NTB) overnight. After adjustment of the concentration, shaking culture was repeated for $2 \mathrm{hr}$. The bacterial suspension was diluted again in NTB at a $1 / 20$ concentration to obtain $3-5 \times 10^{6}$ cells $/ \mathrm{ml}$ of test bacterial suspension. Three standard cloths $(0.4 \mathrm{~g}$ each $)$ processed with each metal were used for the antimicrobial activity test. Each cloth was placed in a vial and autoclaved. A test bacterial suspension $(0.2 \mathrm{ml})$ was used to inoculate the test cloth, and, after culturing at $37^{\circ} \mathrm{C}$ for $18 \mathrm{hr}$, cells were washed out with $20 \mathrm{ml}$ of sterilized buffered saline containing $0.2 \%$ Tween 80 . After serial dilution of the solution obtained by washing with buffered saline, each diluted solution $(0.1 \mathrm{ml})$ was applied to a standard agar plate. After culture for $24-48 \mathrm{hr}$, the number of viable cells was counted. 
As controls, 6 white cotton fabric samples for the JIS color fastness test (JIS 0803 Kanakin No. 3) were used. From the bacterial count in 3 white cotton fabric samples immediately after inoculation (A), that in 3 white fabric samples after 18-hr culture (B), and that in 3 test cloths after 18-hr culture (C), static bacterial activity (b-c): $\log \mathrm{B}-\log \mathrm{C}$, and bactericidal activity $(\mathrm{a}-\mathrm{c}): \log \mathrm{A}-\log \mathrm{C}$, were calculated.

\section{RESULTS AND DISCUSSION}

\section{Preparation of Metal Zeolites}

The goal metal content of each metal zeolite was determined as $5 \mathrm{wt} \%$. In Na substitution by the metal, the metal salt was added after the adjustment of its amount so that the metal weight was $5 \%$ of the metal zeolite weight when all sodium and metal ions had been exchanged.

The Al content in zeolites is high $(\geq 10 \%)$. Therefore, in nitric acid solution, Al may be dissolved, resulting in the elution of all of the metal that has replaced the Na. Therefore each metal zeolite was ashed with nitric acid, and each metal in the solution was determined using ICP-AES. Good substitution was observed, showing a weight ratio of $3-5 \%(30-50 \mathrm{mg} / \mathrm{g})$ for $\mathrm{Ag}, 3-4 \%$ for $\mathrm{Cu}, 3-4 \%$ for $\mathrm{Zn}$, and $2-3 \%$ for $\mathrm{Cr}$. When each metal was measured in the solution after metal substitution, no $\mathrm{Ag}, \mathrm{Cu}$, or $\mathrm{Zn}$ was detected (below detection limits). Novaron AG 300 was similarly analyzed, but Ag was detected at only $0.5-1 \mathrm{mg} / \mathrm{g}(0.05-0.1 \%)$. Since the principle component of the substance carrying $\mathrm{Ag}$ is $\mathrm{Zr}$ in Novaron AG300, Ag may not have been eluted into the nitric acid solution, resulting in the detection of only a low concentration.

\section{Preparation of Standard Processed Cloths}

To select the optimal binder for the fixation of metal antimicrobials to the cloth, the fixation effects of the following binders were evaluated: Kesmon binder KB4900 (Toagosei Co., Ltd.; acrylic type); Light-Epoch S-60NFE (Kyoeisha Chemical Co., Ltd.; silicon acrylic type); Light-Epoch T-23 M (Kyoeisha Chemical Co., Ltd.; acrylic type); and no binder. Zeolites are crystalline minerals composed of $\mathrm{Al}, \mathrm{Si}$, and $\mathrm{Na}^{18)}$ Therefore cloths to which zeolite A-4 was fixed using each binder were prepared, and $\mathrm{Al}$ before and after washing with water was measured using ICP-AES. The attachment rate of each metal antimicrobial was compared. For wash- ing, cloths were shaken using a wrist-action shaker for $1 \mathrm{hr}$ in the JIS shake-flask antimicrobial test (JIS $\mathrm{L}$ 1902-1990). ${ }^{24)}$ As a result, the amount of $\mathrm{Al}$ in processed cloths after washing was $98 \%$ of that before washing using Light-Epock S-60NFE, which showed the lowest reduction rate. In addition, this binder did not contain metals such as $\mathrm{Ag}, \mathrm{Cu}, \mathrm{Zn}$, or Cr. Therefore, using this binder, each metal zeolite or Novaron AG300 was fixed to cloths, and antimicrobial-processed cloths (standard processed cloths) were prepared. Each metal concentration was about $500 \mu \mathrm{g} / \mathrm{g}$ in $1 \%$ and about $1000 \mu \mathrm{g} / \mathrm{g}$ in $2 \%$ processed cloths. As a blank, cloths processed with only this binder (Light-Epoch S-60NFE, 1\% and $2 \%$ ) were prepared and similarly analyzed. The results of metal analysis in cloths processed with each metal antimicrobial are shown in Table 1 (1). The low Ag concentration in cloths processed with Novaron AG300 may be due to the incomplete ashing of $\mathrm{Zr}$ as the principle component of the carrier, as was observed in the ashing of this antimicrobial.

\section{Metal Elution with Artificial Sweat/Saliva and Purified Water \\ Metal Elution from Metal Antimicrobials (Metal} Zeolites, AG300): Metals are readily eluted with sweat/saliva from antimicrobials (metal zeolites, AG300). Since extraction for a long time results in the elution of all $\mathrm{Cu}$ or $\mathrm{Zn}$, differences in the elution tendency among extracting solutions or among antimicrobials cannot be clarified. Therefore the elution tendency of each metal was observed by extraction for $1 \mathrm{~min}$. The results are shown in Table 2 . Each metal was eluted with artificial sweat/saliva but not with purified water. Since metals in zeolites and AG300 are eluted after ion exchange with $\mathrm{Na}$ ions, ${ }^{18-20)}$ their elution may occur after contact with artificial sweat/saliva with a large amount of $\mathrm{Na}$ ions. Elution did not occur with neutral, pure water without $\mathrm{Na}$ ions. These findings suggest the function of antimicrobials: "Metals are not eluted with water during washing but eluted during sweating with clothes on, exerting antimicrobial effects."

Compared with $\mathrm{Cu}$ or $\mathrm{Zn}$ elution, the level of Ag elution with artificial sweat/saliva was low and similar between the Ag zeolite and AG300. This may be because large amounts of $\mathrm{Cl}$ ions are contained in artificial sweat/saliva, and $\mathrm{Ag}$ ions bind to $\mathrm{Cl}$ ions, forming $\left[\mathrm{AgCl}_{2}\right]^{-}$, which is slightly soluble in water.

The amount of $\mathrm{Cu}$ elution from the $\mathrm{Cu}$ zeolite was high with both sweat/saliva, but no $\mathrm{Cu}$ was 
Table 1. Metal Elution with Artificial Sweat/Saliva from Standard Processed Cloths

\begin{tabular}{|c|c|c|c|c|c|}
\hline \multirow[t]{3}{*}{ Type of processed cloth } & \multirow{3}{*}{$\begin{array}{l}\text { (1) Concentration of metal } \\
\text { in processed cloth } \\
\text { (ICP-AES) } \\
\left.(\mu \mathrm{g} / \mathrm{g})^{a}\right)\end{array}$} & \multicolumn{4}{|c|}{$\begin{array}{l}\text { (2) Amount of eluted metal from } \\
\text { standard processed cloth } \\
\text { (ICP-MS) }\end{array}$} \\
\hline & & Acidic sweat & Alkaline sweat & Saliva & Purified water \\
\hline & & \multicolumn{4}{|c|}{$(\mu \mathrm{g} / \mathrm{g})^{b)}$} \\
\hline Ag zeolite (1\% processed cloth) & 477 & 2.12 & 8.95 & 6.21 & N.D. \\
\hline Ag zeolite ( $2 \%$ processed cloth) & 1087 & 5.38 & 18.28 & 8.39 & N.D. \\
\hline $\mathrm{Cu}$ zeolite ( $1 \%$ processed cloth) & 547 & 514.95 & 353.09 & 530.70 & N.D. \\
\hline $\mathrm{Cu}$ zeolite ( $2 \%$ processed cloth) & 1398 & 1295.80 & 793.09 & 1229.10 & N.D. \\
\hline Zn zeolite (1\% processed cloth) & 563 & 77.82 & 404.14 & 741.97 & N.D. \\
\hline Zn zeolite ( $2 \%$ processed cloth) & 1278 & 174.83 & 752.49 & 1364.80 & N.D. \\
\hline Cr zeolite (1\% processed cloth) & 656 & N.D. & N.D. & N.D. & N.D. \\
\hline Cr zeolite (2\% processed cloth) & 1051 & N.D. & N.D. & N.D. & N.D. \\
\hline Novaron AG300 (1\% processed cloth) & 195 & 2.30 & 10.08 & 4.61 & N.D. \\
\hline Novaron AG300 ( $2 \%$ processed cloth) & 333 & 4.57 & 19.87 & 7.72 & N.D. \\
\hline
\end{tabular}

The metal concentrations in the table show those of the metal type as a processing agent. $a$ ) Detection limit; less than $0.1 \mu \mathrm{g} / \mathrm{g}$. Three samples of each cloth type were analyzed $(n=3, \mathrm{CV}=0.6-25.1 \%) . b$ ) N.D.; Not detected, less than $0.001 \mu \mathrm{g} / \mathrm{g}$. Three extract samples of each cloth type were analyzed $(n=3, \mathrm{CV}=1.3-20.1 \%)$. $1 \%$ processed cloth; White cotton fabric processed with a metal agent at $1 \%$ of the weight of the fiber (o.w.f). $2 \%$ processed cloth; White cotton fabric processed with a metal agent at $2 \%$ o.w.f. Eluant volume, $15 \mathrm{ml}$; sample amount, $0.75 \mathrm{~g}$; elution time, $1 \mathrm{hr}$; temperature, room temperature.

Table 2. Metal Elution with Artificial Sweat/Saliva from Inorganic Antimicrobials ( $\mu \mathrm{g} / \mathrm{g})$

\begin{tabular}{lccccc}
\hline \hline Inorganic antimicrobials & Element & Acidic sweat & Alkaline sweat & Saliva & Purified water \\
\hline Ag zeolite & $\mathrm{Ag}$ & 7.29 & 26.00 & 14.50 & N.D. \\
Cu zeolite & $\mathrm{Cu}$ & 10100.00 & 8890.00 & 8110.00 & N.D. \\
Zn zeolite & $\mathrm{Zn}$ & 379.00 & 6210.00 & 3190.00 & N.D. \\
Cr zeolite & $\mathrm{Cr}$ & N.D. & N.D. & N.D. & N.D. \\
AG300 & $\mathrm{Ag}$ & 4.12 & 13.20 & 7.00 & N.D. \\
\hline
\end{tabular}

N.D.; Not detected, less than $0.01 \mu \mathrm{g} / \mathrm{g}$. Three samples of each antimicrobial type were analyzed $(n=3, \mathrm{CV}=3.6-20.3 \%)$. The metal concentrations in the table show those of the metal type as a processing agent. None of the 4 types of metal was eluted from zeolite A-4.

eluted with water. The level of $\mathrm{Cu}$ elution was the highest with acidic sweat, followed in order by alkaline sweat and saliva. $\mathrm{Cu}$ forms chelates with amino acids (such as histidine). ${ }^{25-27)}$ Such chelates are readily eluted with water. Histidine was added to artificial sweat, which may be associated with the higher amount of elution with sweat than with saliva. In addition, $\mathrm{Cu}$ is very soluble in acidic solution, which may be associated with the higher rate of elution with acidic than with alkaline sweat. Organic acids such as lactic acid also facilitate metal elution from zeolites. ${ }^{25}$ ) Therefore lactic acid in saliva also promotes metal elution. However, histidine may have had a more marked influence than lactic acid on $\mathrm{Cu}$ elution.

The amount of $\mathrm{Zn}$ elution from the $\mathrm{Zn}$ zeolite was also high, and the highest with alkaline sweat, followed in order by saliva and acidic sweat. $\mathrm{Zn}$ is a typical amphoteric metal that is highly soluble either in acidic or alkaline solution. However,
$\mathrm{Zn}$ ions bound to $\mathrm{SiO}_{2}$ as a component of the zeolite are more readily exchanged with $\mathrm{Na}$ ions in an alkaline environment, ${ }^{18)}$ which may be associated with the most marked elution with alkaline sweat. When acidic saliva is compared with acidic sweat, the lower $\mathrm{pH}$ and the presence of lactic acid in saliva may have resulted in a higher level of elution with saliva. $\mathrm{Zn}$ is not affected by histidine under the conditions. $^{27)}$

$\mathrm{Cr}$ elution from the $\mathrm{Cr}$ zeolite was negligible. This may be because $\mathrm{Cr}$ is firmly carried by zeolite.

None of the 4 types of metal was detected from artificial sweat, artificial saliva, purified water, or zeolite A-4.

Metal Elution from Standard Processed Cloths: This study was aimed at not only the observation of the amount of metal elution but also at the evaluation of the influences of the elution concentration on indigenous bacteria in the skin. Therefore elution conditions were evaluated using those for 
antimicrobial tests as a reference. The JIS shakeflask antimicrobial test (JIS L 1902-1900) allows the application of elution with artificial sweat. In this test method, each cloth $(0.75 \mathrm{~g})$ and test solution $(75 \mathrm{ml})$ are placed in a $200-\mathrm{ml}$ Erlenmeyer flask and shaken using a wrist-action shaker at room temperature $\left(20-30^{\circ} \mathrm{C}\right)$ for $1 \mathrm{hr}$. The ratio of the sample weight to the solution volume (bath ratio) is $1: 100$. Considering the actual state of elution from cloth with human sweat/saliva, this volume of solution is excessive. To determine the minimum bath ratio, the amount of solution, amount of the sample that allows adequate stirring and collection as an eluate, and volume of solution were changed in the range from 3 to $15 \mathrm{ml}$. When the volume of solution was small, the sample attached to the container wall, and stirring was inadequate. Adequate stirring was possible with $15 \mathrm{ml}$ of solution, and a sufficient amount of eluate for analysis could be collected. Therefore, the amounts of solution and sample were determined to be $15 \mathrm{ml}$ and $0.75 \mathrm{~g}$, respectively (bath ratio, $1: 20$ ). Elution experiments using each standard processed cloth were performed. The results are shown in Table 1 (2). From the processed cloths, metals were not eluted with purified water but were eluted with sweat/saliva. The metal elution rate was lower for the processed cloths in which the antimicrobial is covered with the binder than for the antimicrobials alone. In the processed cloths, the influences of an organic acid (lactic acid) and amino acid (histidine) with large molecular size, which have difficulty passing through the binder film, decrease, while those of $\mathrm{Na}$ ions and $\mathrm{H}$ ions $(\mathrm{pH})$ with small molecular size may increase.

The level of elution from the cloths processed with the Ag zeolite or AG300 showed a tendency similar to that from the Ag antimicrobials, being low with sweat/saliva and similar between the cloths processed with the two antimicrobials.

The amount of $\mathrm{Cu}$ elution from the $\mathrm{Cu}$ zeoliteprocessed cloths showed a tendency similar to that from the $\mathrm{Cu}$ zeolite, being high with sweat/saliva and zero with pure water. The order of eluting ability was saliva $=$ acidic sweat $>$ alkaline sweat. Most $\mathrm{Cu}$ was eluted with saliva and acidic sweat.

The amount of $\mathrm{Zn}$ elution from the $\mathrm{Zn}$ zeoliteprocessed cloths was the highest with saliva, followed in order by alkaline and then acidic sweat. The ratio of $\mathrm{Zn}$ elution with saliva increased for the $\mathrm{Zn}$ zeolite-processed cloths compared with the $\mathrm{Zn}$ zeolite; most $\mathrm{Zn}$ was eluted from the processed cloths. No $\mathrm{Cr}$ was eluted from the $\mathrm{Cr}$ zeolite- processed cloths. Similar elution experiments were performed for cloths processed with the binder alone ( $1 \%$ and $2 \%$ ), but none of the 4 types of metals was eluted.

Metal Elution from Commercially Available Antimicrobial-processed Products: We previously performed metal analysis of 86 regions of 40 antimicrobial-processed products. ${ }^{16,17)}$ Similar elution experiments were performed for 20 regions of the 40 products that showed $\mathrm{Ag}, \mathrm{Cu}, \mathrm{Zn}$, or $\mathrm{Cr}$ at a high concentration. The results are shown in Table 3. Table 3 also shows the metal contents (results of analysis using ICP-AES) of the products. For ICP-AES analysis and elution experiments with sweat/saliva/purified water, 5 measurement areas considered to be similarly processed were used. The elution patterns were not always consistent with those for the standard processed cloths. The amount of metal elution with water from these products was low, but that with sweat/saliva was high.

Ag elution from 4 products (nos. 7, 16, 19, and 20) in which Ag was detected using ICP-AES analysis was as low as that from the Ag-processed standard cloths. Ag elution from no. 7 was not detected, possibly due to a low Ag content. However, the products applied in this experiment contained a large amount of $\mathrm{Al}$ and were considered to use the Ag zeolite based on the indications of the product. ${ }^{17)}$

The amount of $\mathrm{Cu}$ elution from 7 products (nos. $2,4,13-16$, and 18) in which $\mathrm{Cu}$ was detected using ICP-AES analysis was lower than that from the $\mathrm{Cu}$ zeolite-processed cloths (standard processed cloths). The products evaluated in elution experiments may have been processed with other methods. The OEKOTEX Standard provides a limit value for $\mathrm{Cu}$ elution with artificial sweat/saliva of 25 (infants)-50 ppm/fiber. In the OEKOTEX Standard, the elution method, volume of solution, elution time, and metal measurement methods are closed. Therefore simple comparison with the results of this study is impossible, but $20 \mathrm{ppm}$ was eluted with artificial saliva from socks (no. 4).

Based on values of ICP-AES analysis, there were 15 products processed with $30 \mathrm{ppm}$ or more of $\mathrm{Zn}^{17}$ ) (nos. 1, 3, 5-9, 12-15, and 17-20) among those used in elution experiments. The amount of Zn elution tended to be high for the commercially available products as well as the standard cloths: most $\mathrm{Zn}$ was eluted with saliva from some products (nos. 3, 7, 19, and 20). However, the amount of $\mathrm{Zn}$ elution was low from 2 products (nos. 17 and 18), 
Table 3. Metal Elution with Artificial Sweat/Saliva from Commercially Available Products

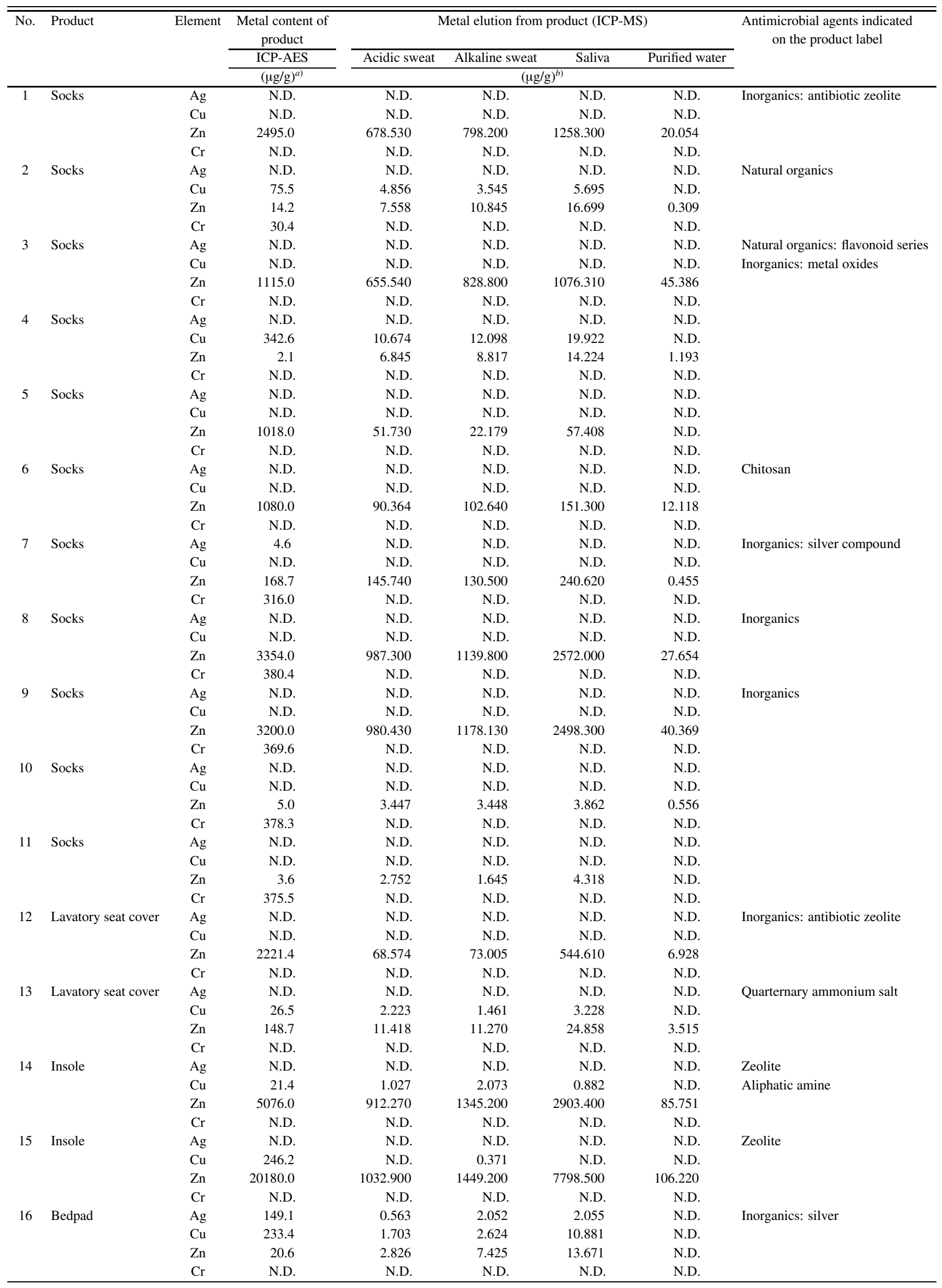


Table 3. Continued

\begin{tabular}{|c|c|c|c|c|c|c|c|c|}
\hline \multirow[t]{3}{*}{ No. } & \multirow[t]{3}{*}{ Product } & \multirow[t]{3}{*}{ Element } & Metal content of & \multicolumn{4}{|c|}{ Metal elution from product (ICP-MS) } & \multirow{3}{*}{$\begin{array}{c}\text { Antimicrobial agents indicated } \\
\text { on the product label }\end{array}$} \\
\hline & & & ICP-AES & Acidic sweat & Alkaline sweat & Saliva & Purified water & \\
\hline & & & $(\mu \mathrm{g} / \mathrm{g})^{a)}$ & \multicolumn{4}{|c|}{$(\mu \mathrm{g} / \mathrm{g})^{b)}$} & \\
\hline \multirow[t]{4}{*}{17} & Sheet/cover & $\mathrm{Ag}$ & N.D. & N.D. & N.D. & N.D. & N.D. & \\
\hline & & $\mathrm{Cu}$ & N.D. & N.D. & N.D. & N.D. & N.D. & \\
\hline & & $\mathrm{Zn}$ & 2328.0 & 2.521 & 2.988 & 111.180 & N.D. & \\
\hline & & $\mathrm{Cr}$ & N.D. & N.D. & N.D. & N.D. & N.D. & \\
\hline \multirow{3}{*}{18} & & $\mathrm{Cu}$ & 36.5 & 2.952 & 0.920 & 5.850 & 1.498 & \\
\hline & & $\mathrm{Zn}$ & 294.2 & 4.787 & 3.197 & 16.539 & 3.490 & \\
\hline & & $\mathrm{Cr}$ & N.D. & N.D. & N.D. & N.D. & N.D. & \\
\hline \multirow[t]{4}{*}{19} & Undershirt & $\mathrm{Ag}$ & 49.3 & 1.220 & 2.749 & 1.653 & N.D. & Silver zeolite \\
\hline & & $\mathrm{Cu}$ & N.D. & N.D. & N.D. & N.D. & N.D. & \\
\hline & & $\mathrm{Zn}$ & 205.0 & 152.660 & 212.480 & 348.000 & 6.403 & \\
\hline & & $\mathrm{Cr}$ & N.D. & N.D. & N.D. & N.D. & N.D. & \\
\hline \multirow{3}{*}{20} & & $\mathrm{Cu}$ & N.D. & N.D. & N.D. & N.D. & N.D. & \\
\hline & & $\mathrm{Zn}$ & 200.0 & 142.500 & 245.480 & 332.410 & 9.044 & \\
\hline & & $\mathrm{Cr}$ & N.D. & N.D. & N.D. & N.D. & N.D. & \\
\hline
\end{tabular}

a) N.D.; Not detected, less than $0.1 \mu \mathrm{g} / \mathrm{g}$. b) N.D.; Not detected, less than $0.001 \mu \mathrm{g} / \mathrm{g}$.

Table 4. Antimicrobial Activity of Standard Processed Cloth

\begin{tabular}{lllllll}
\hline \hline Type of processed cloth & \multicolumn{2}{c}{ S. aureus } & & \multicolumn{2}{c}{ K. pneumoniae } \\
\cline { 2 - 3 } \cline { 5 - 6 } & $\mathrm{a}-\mathrm{c}$ & $\mathrm{b}-\mathrm{c}$ & & $\mathrm{a}-\mathrm{c}$ & $\mathrm{b}-\mathrm{c}$ \\
\hline Ag zeolite (1\% processed cloth) & 2.4 & 4.1 & & 2.1 & 4.3 \\
Ag zeolite (2\% processed cloth) & 3 & 4.5 & & 2.8 & 4.3 \\
Cu zeolite (1\% processed cloth) & 1.3 & 3.2 & & 2.8 & 4.3 \\
Cu zeolite (2\% processed cloth) & 2.7 & 4.5 & & 2.8 & 4.3 \\
Zn zeolite (1\% processed cloth) & 0.8 & 2.7 & & -0.7 & 1 \\
Zn zeolite (2\% processed cloth) & 1.4 & 3.3 & & -0.5 & 1.1 \\
Cr zeolite (1\% processed cloth) & -1.7 & 0.1 & & -0.3 & 1.4 \\
Cr zeolite (2\% processed cloth) & -1.6 & 0.2 & & -0.5 & 1.1 \\
Novaron AG300 (1\% processed cloth) & 0.5 & 2 & & 2.1 & 4.3 \\
Novaron AG300 (2\% processed cloth) & 2.4 & 3.9 & & 2.1 & 4.3 \\
LIGHT-EPOCH (1\% processed cloth) & -1.3 & 0.3 & & -1.4 & 0.2 \\
LIGHT-EPOCH (2\% processed cloth) & -0.4 & 1.2 & & -1.7 & 0.1 \\
\hline
\end{tabular}

A; Number of inoculated bacteria. B; Number of bacteria on the standard white cloth contacted for $18 \mathrm{hr}$. C; Number of bacteria on the test cloth after incubation for $18 \mathrm{hr} . \mathrm{a}=\log \mathrm{A}, \mathrm{b}=\log \mathrm{B}, \mathrm{c}=$ $\log$ C. Bactericidal activity level, a-c; bacteriostatic activity level, b-c.

probably because they were waterproof. Based on the $\mathrm{Al}$ content (ICP-AES analysis) and product indications, 10 products (nos. 1, 3, 7-9, 12, 14, 15, 19, and 20) were considered to use a $\mathrm{Zn}$ zeolite. ${ }^{17)}$

Patients with metal allergy due to Cr have frequently been reported. ${ }^{12)}$ The OEKOTEX Standard provides a limit of $\mathrm{Cr}$ elution with artificial sweat/saliva of 1 (infants)-2 ppm. ${ }^{13,14)}$ Elution experiments showed no $\mathrm{Cr}$ elution from 6 products (nos. 2 and 7-11) in which $\mathrm{Cr}$ was detected with ICP-AES analysis.

\section{Evaluation of the Antimicrobial Activity of Inor- ganic Antimicrobial-Processed Cloths}

The antimicrobial activity of standard cloths processed with metal zeolites $(\mathrm{Ag}, \mathrm{Cu}, \mathrm{Zn}$, and $\mathrm{Cr})$ or the silver antimicrobial AG300 was evaluated using the antimicrobial test (JIS L 1902: 2002). ${ }^{21)}$ The results are shown in Table 4. The antimicrobial effects of cloths processed with $\mathrm{Ag}$ (Ag zeolite, AG300) or $\mathrm{Cu}$ were high against both $S$. aureus and $K$. pneumoniae. The Zn-processed cloths exhibited antimicrobial effects against $S$. aureus. The Cr-processed cloths and cloths processed with the binder alone (blank) had no antimicrobial effects.

Although the rate of Ag ion elution from the Agprocessed cloths was low, the highest antimicrobial effects of Ag-processed cloths may be due to the high antimicrobial activity of $\mathrm{Ag}$ ions. The strong antimicrobial effects of $\mathrm{Cu}$-processed cloths may be 
due to the large amount of $\mathrm{Cu}$ ion elution, as shown in Table 1, as well as the marked antimicrobial activity of $\mathrm{Cu}$ ions. Although the amount of $\mathrm{Zn}$ elution from the $\mathrm{Zn}$-processed cloths was high, its low antimicrobial effects may be due to a lower antimicrobial activity of $\mathrm{Zn}$ than that of $\mathrm{Ag}$ or $\mathrm{Cu}{ }^{19,20)} \mathrm{No} \mathrm{Cr}$ was eluted from the Cr-processed cloths, suggesting no antimicrobial effects.

Acknowledgement This study was supported by a Grant-in-Aid for Scientific Research from the Ministry of Health, Labour and Welfare (Chemical Risk Research Project) "Study on safety evaluation of antimicrobial products and transmission of product information."

\section{REFERENCES}

1) Japan Textile Evaluation Technology Council (2006) http://www.sengikyo.or.jp/pdf/kohkin_bunrui.pdf

2) Okazaki, K. (2004) Antimicrobial/deodorant/ bacteriostatic. J. Soc. Fiber Technol., 60, 335-345.

3) Nakashima, H., Miyano, N., Matsunaga, I., Nakashima, N. and Kaniwa, M. (2007) Research on the marketing status of antimicrobial products and the use of antimicrobial agents indicated on the product labels: From 1991 through 2005. Yakugakuzasshi, 127, 865-888.

4) Nakashima, H., Ohmori, Y., Isama, K., Matsunaga, I., Miyano, N., Asano, Y., Teraji, Y. and Kaniwa, M. (1998) Studies on safety evaluation of antimicrobial/deodorant agents: Establishment of research method and research results of commercially available products. Jpn. J. Toxicol. Environ. Health, 44, 138-149.

5) Nakashima, H. (1998) Present status of the use of antimicrobial agents-A survey in Osaka Prefecture. In All about Antimicrobials (Yuge, O. and Yokoyama, H., Eds.), Sen-isha, Osaka, pp. 360-374.

6) Nakashima, H., Matsunaga, I., Miyano, N., Miyauchi, R., Serikawa, H., Masuda, Y., Isama, K., Igarashi, Y. and Kaniwa, M. (2000) Studies on safety evaluation of antimicrobial/deodorant agents: Marketing research on antimicrobial/deodorant products in Osaka Prefecture (from 1991 to 1999). Bulletin of Osaka Prefecture Institute of Public Health, 38, 21-32.

7) Hayashi, S., Dekio, S., Kakizoe, E. and Jidoi, J. (1995) A case of contact dermatitis from the microphone of an ambulatory blood pressure monitoring system. Environ. Dermatol., 2, 283-286.

8) Ikehata, K. and Sugai, T. (1996) A case of contact allergy from nickel, cobalt and rosin. Environ. Dermatol., 3, 103-107.

9) Suzuki, K. (1998) Study on optimum patch test materials and their optimum concentrations for zinc and manganese contact allergy and annual variations of the patients with facial melanosis. Environ. Dermatol., 5, 76-85.

10) Nakamichi, H., Hirano, S., Sibagaki, R., Kishimoto, S. and Yasuno, H. (1998) Three cases of contact dermatitis due to zinc oxide simple ointment. Environ. Dermatol., 5, 121-125.

11) Chinen, T., Kato, H., Fukawa, M., Abe, N., Morita, C., Saito, M., Taba, M. and Itoh, M. (2001) A case of contact dermatitis due to zinc oxide simple ointment. Environ. Dermatol., 8, 135-140.

12) Ministry of Health, Labour and Welfare. Hospital report of monitoring of health hazards associated with household products (1995-2005) http:// www.nihs.go.jp/mhlw/chemical/katei/monitor(new). html

13) International Oeko-Tex Association (1992) Oeko-Tex Standard 100, http://www.oeko-tex.com/ OekoTex100_PUBLIC/index.asp?cls $=02$

14) Japan Dyer's Inspection Institute Foundation (Ed.) (2004) Oeko-tex, Oeko-tex Corporation, Japan Dyer's Inspection Institute Foundation, Tokyo, http://www.hi-ho.ne.jp/n-senken/index.htm

15) Kaniwa, M. (2006) Study on safety evaluation of antimicrobial products and transmission of product information. A Report of Health, Labour and Welfare Scientific Research, 2003-2005 (Chemical Risk Research Project), http://mhlw-grants.niph.go. jp/niph/search/NIST00.do.

16) Nakashima, H. (2006) Study on safety evaluation of antimicrobial products and transmission of product information. A Report of Shared Health, Labour and Welfare Scientific Research, 2003-2005, http:// mhlw-grants.niph.go.jp/niph/search/NIST00.do.

17) Nakashima, H. and Ooshima, T. (2007) Analysis of inorganic antimicrobial agents in antimicrobial products: Evaluation of a screening method by Xray fluorescence spectrometry and the measurement of metals by Inductively coupled plasma atomic emission spectroscopy. J. Health Sci., 53, 423-429.

18) Goto, Y. (1993) Product structure built of atoms Zeolite. Ryukoku Rikou Journal, 5, 13-20.

19) Seino, Y., Moriyasu, N., Hiyama, K. and Goto, Y. (1995) Antibacterial activities of zeolite-treated cotton cloth. J. Antibact. Antifung. Agents, 23, 145149.

20) Hiyama, K., Moriyasu, N., Omori, T., Miyagawa, O., Seino, Y. and Goto, Y. (1995) Artificial efficiency of Ag- and Zn-zeolites and the bacterial ac- 
tion of Ag- and Zn-zeolite-kneaded polyethylene films. J. Antibact. Antifung. Agents, 23, 197-203.

21) Japanese Industrial Standard Community (2002) Testing for antimicrobial activity and efficacy on the textile products (JIS L 1902: 2002). Japanese Standards Association, Tokyo.

22) Japanese Industrial Standard Community (2004) Test method for color fastness to perspiration (JIS L 0848: 2004). Japanese Standards Association, Tokyo.

23) British Standard Specification for safety harnesses (including detachable walking reins) for restraining children when in perambulators (baby carriages), pushchairs and high chairs and when walking. BS 6684: 1987.

24) Japanese Industrial Standard Community (1990)
Shake-flask antimicrobial test method (JIS L 1902: 1990). Japanese Standards Association, Tokyo.

25) Sakaguchi, T. and Ueno, K. (1967) Stability constant. In Metallic Chelate, vol. 3 (Sakaguchi, T. and Ueno, K., Eds.), Nankoudou Press, Tokyo, pp. 8, 50, 179.

26) Kiyozumi, M., Honda, T., Hiroto, K., Kitajima, K., Ohnishi, M. and Kojima, S. (1988) Effects of essential metals on small intestinal absorption of Lhistidine and L-leucine in rats. Eisei Kagaku, 34, 531-535.

27) Martell, A. E. and Smith, R. M. (1974) Aminocarboxylic acids, histidine. In Critical Stability Constants, vol. 1 (Martell, A. E. and Smith, R. M., Eds.), Plenum Press, New York, pp.60-61. 